\title{
KARAKTERISTIK SISTEM TRANSPORTASI DI SEPANJANG RUAS JALAN KM.0 - KM.12 KOTA SORONG
}

\author{
Elfirah Lukman ${ }^{1)}$ \\ 1) Program Studi Teknik Sipil Universitas Muhammadiyah Sorong \\ Jl. Pendidikan No 27 Kota Sorong, Propinsi Papua Barat \\ Email : fhirazahira@gmail.com
}

\begin{abstract}
ABSTRAK
Kota Sorong merupakan wilayah yang membentang sepanjang pesisir bagian barat Propinsi Papua Barat. Salah satunya adalah sepanjang ruas jalan yang merupakan salah satu transportasi jalan utama atau jalan poros Kota Sorong yaitu Km.0 - Km.12 yang di lalui oleh masyarakat. Tujuan penelitian untuk menganalias ruas jalan yang ada di Kota Sorong. Metode yang digunakan untuk melakukan pengamatan secara langsung terhadap ruas jalan utama yang ada di Kota Sorong. Karakteristik sistem transportasi di ruas jalan utama Kota Sorong adalah ruas jalan utama mempunyai kinerja yaitu kecepatan arus masih stabil, kecepatan dan pergerakan lebih ditentukan oleh volume tinggi kapasitas lahan parkir di sarana umum belum optimal, nilai kebisingan di ruas jalan utama melebihi standar yang berlaku, dan keberadaan on street parking akibat parkir liar pada ruas jalan utama.
\end{abstract}

Kata Kunci : Transportasi,Ruas jalan,Kota Sorong

\section{PENDAHULUAN}

Kota Sorong merupakan wilayah yang membentang sepanjang pesisir bagian barat Propinsi Papua Barat. Kecenderungan peningkatan jumlah kendaraan bermotor yang beroperasi, akan menambah beban lalu lintas dan menimbulkan berbagai permasalahan yang dapat mengganggu sebagian besar masyarakat perkotaan. Sebagai salah satu contohnya yaitu meningkatnya intensitas polusi suara berupa kebisingan bagi lingkungan di sekitar jalan tersebut. Sumber bising lalu lintas jalan diantaranya berasal dari kendaraan bermotor baik roda dua, roda empat maupun kendaraan berat yang sumber penyebab bisingnya antara lain dari bunyi klakson kendaraan, suara knalpot akibat penekanan pedal gas secara berlebihan dan penggunaan knalpot racing, Tiap-tiap kendaraan menghasilkan kebisingan, namun sumber dan besarnya dari kebisingan dapat sangat bervariasi tergantung jenis kendaraan.

Sepanjang ruas Jalan Ahmad Yani- Jalan Basuki Rahmat yang menjadi objek penelitian merupakan ruas jalan yang berdekatan dengan banyak sarana umum, pemukiman penduduk, sarana pendidikan dan kesehatan serta tempat ibadah yang berhadapan langsung dengan jalan. Jalan Ahmad Yani- Jalan Basuki Rahmat merupakan jalan yang volume lalu lintasnya cukup padat juga kecepatan kendaraan yang lumayan tinggi, terutama bila masuk saat-saat jam sibuk yang memungkinkan terjadinya kenaikan intensitas polusi suara. Sehingga penulis sangat tertarik untuk membahas dan mengkaji karakeristik transportasi sepanjang ruas jalan dari km.0 km.12 Kota Sorong. 


\section{METODOLOGI}

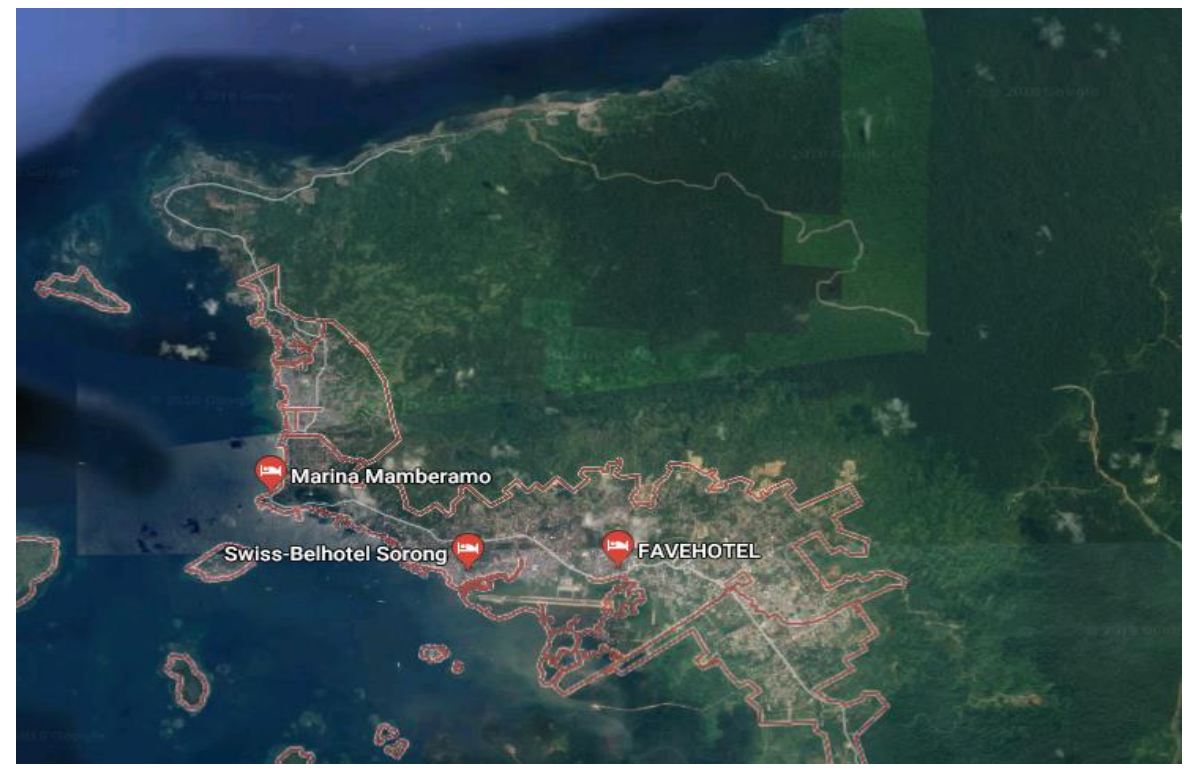

Gambar 1. Lokasi Studi

Tahapan Penyusunan Artikel :

1. Penentuan tema

2. Penelusuran artikel yang bersesuaian dengan tema yang diambil (melalui google scholar)

3. Analisa komparatif terhadap artikel yang didapatkan dari google scholar

4. Membuat kesimpulan untuk menjawab tujuan penulisan

Semua metode penulisan dan analisa dalam artikel ilmiah ini merujuk pada panduan penulisan tugas akhir Fakultas Teknik Universitas Muhammadiyah Sorong tahun 2014 (Pristianto, Amri, \& Rusdi, 2014).

\section{HASIL DAN PEMBAHASAN}

Penelitian dengan tema yang sama.

Beberapa hasil penelitian terkait tema artikel ini adalah sebagai berikut:

1. Menurut Pristianto (2016) yang meneliti tentang kebisingan di Jalan Ahmad Yani Kota Sorong, didapat kesimpulan antara lain :

Rata-rata angkutan yang masuk adalah sebanyak 56 angkutan/hari dan angkutan yang keluar sebanyak 51 angkutan/hari. Beberapa hari sebelum perayaan natal masyarakat yang datang dari pulau sangat banyak, hal ini karena mereka harus mempersiapkan perlengkapan untuk menyambut hari raya natal.

Persentase hasil interview pada masyarakat bahwa :

a). Usia pengguna angkutan melalui sungai remu sebesar $33 \%$ yang terdiri pada usia 20-29 tahun

b). Pengguna angkutan antar pulau ini di dominasi oleh laki-laki karena mereka yang mengemudikan alat angkutan.

c). Jenis angkutan yang sering di gunakan masyarakat melalui sungai remu adalah Long boat, kapal layar/kapal venes, speed boat,sampan, katinting, taxi laut.

d). Tujuan masyarakat dari pedalaman datang ke Sorong sebagai pusat kota adalah mereka yang berbelanja dan berdagang. 
e). Intensitas pemakaian angkutan antar pulau melalui sungai remu adalah sebesar 43,3\% karena angkutan yang di gunakan masyarakat adalah taxi laut yang beroperasi seminggu $2 \mathrm{kali}$, yaitu pada hari senin dan rabu.

2. Faktor-faktor yang mempengaruhi kelancaran lalu lintas melalui sungai remu adalah kapal-kapal yang parkir pada sepanjang aliran sungai menuju bagian hulu (dermaga), tanggul sungai remu, dan sedimentasi pada dasar sungai remu serta terdapat angkutan sedimen suspensi berupa sampah yang mengapung pada sepanjang aliran sungai remu. Dari hasil penelitian mengenai Tinjauan kondisi muara sungai remu dalam menunjang kelancaran angkutan antar pulau di kota Sorong sudah lancar hal ini karena lebar muara sungairemu sudah cukup menunjang bagi kapalkapal yang keluar dan masuk, akan tetapi masyarakat sangat terganggu karena masih banyak kapal-kapal yang parkir pada sepanjang aliran sungai menuju hulu (dermaga) dan masih banyaknya sampah disepanjang aliran sungai remu

2. Menurut Pristianto \& Hidayati (2017) yang meneliti tentang kebisingan lalu lintas di ruas Jalan Basuki Rahmat Kota Sorong, didapat kesimpulan antara lain :

a. Volume Lalu-Lintas pada ruas jalan nBasuki Rahmat, volume kendaraan Maksimum pada jam puncak adalah 1.163,85 kend/smp, Nilai Derajat Kejenuhan (DS) pada ruas jalan Basuki Rahmat berdasarkan hasil analisa data lapangan adalah 0,45. Dari nilai derajat kejenuhan tersebut maka diperoleh tingkat pelayanan berada pada tingkat pelayanan B. Tingkat pelayanan B menunjukan bahwa pada ruas jalan Basuki Rahmat arus stabil, pengemudi masih diberi kebebasan dalam memilih kecepatan, kecepatan rata-rata pada ruas jalan Basuki Rahmat adalah 40,00 km/jam

b. Pengaruh peningkatan volume kendaraan terhadap penurunan tingkat pelayanan jalan berdasarkan hasil penelitian yang berlangsung selama 14 hari yang dimulai pada tanggal 07 Januari 2017 - 20 Januari 2017. Kondisi jalan yang menjadi tempat penelitian dalam kondisi stabil yaitu tingkat pelayanan jalan berada pada tingkat pelayanan B dengan nilai sebesar 0,45. Dalam kondisi ini berdasarkan MKJI 1997 tingkat pelayanan jalan masih dalam kondisi baik yakni dengan klasifikasi tingkat pelayanan jalan semua berada di kisaran kelas B (dalam zona arus stabil, pengemudi memiliki kebebasan yang cukup dalam memilih kecepatan)

3. Menurut Desembardi, Sukrisman, Pristianto, \& Ulayanto (2018) yang meneliti tentang kinerja ruas Jalan AM Sangadji Gonof Km 12 Kota Sorong, didapat kesimpulan antara lain :

a. Berdasarkan analisa jalan perkotaan menggunakan pedoman MKJI 1997, kondisi ruas jalan A.M Sangaji Gonof Km.12 akibat pengaruh kelas hambatan samping sedang/medium didapat faktor penyesuaian sebesar 0,95 sehingga di dapat kapasitas $1654 \mathrm{smp} /$ jam dengan nilai derajat kejenuhan 0,46. Kemudian pada skenario 1 dan 2 akibat pengaruh kelas hambatan samping rendah/low didapat faktor penyesuaian sebesar 0,97 sehingga didapat kapasitas 1689 Smp/Jam dengan nilai derajat kejenuhan 0,44. Lalu pada skenario 3 akibat pengaruh kelas hambatan samping sangat rendah/very low didapat faktor penyesuaian sebesar 0,99 sehingga didapat kapasitas $1724 \mathrm{smp} / \mathrm{jam}$ dengan nilai derajat kejenuhan 0,43 dapat disimpulkan bahwa peningkatan nilai penyesuaian hambatan samping dapat meningkatkan kapasitas ruas jalan dan dapat menurunkan nilai derajat kejenuhan. 
b. Berdasarkan rumusan masalah poin dua, kinerja ruas jalan A.M. Sangaji Gonof Km.12 Kota Sorong pada kondisi existing/saat ini didapat jumlah bobot hambatan samping sebesar 333 dengan kelas hambatan samping sedang/medium, didapat nilai kecepatan arus bebas kendaraan ringan (FV) sebesar 32,61 km/jam, kapasitas total adalah $1654 \mathrm{smp} / \mathrm{jam}$, nilai derajat kejenuhan $0,46, \mathrm{~V}_{\mathrm{LV}}=28,00$ $\mathrm{km} / \mathrm{jam}$, nilai $\mathrm{TT}=25,71$ detik dan nilai tingkat pelayanan jalan $\mathrm{C}$ sedangkan kinerja ruas jalan menggunakan skenario 3 didapat jumlah bobot hambatan samping sebesar 99,5 dengan kelas hambatan samping sangat rendah/ very low, didapat nilai kecepatan arus bebas kendaraan ringan (FV) sebesar 34,32 km/jam, kapasitas total adalah $1724 \mathrm{smp} / \mathrm{jam}$, nilai derajat kejenuhan $0,43, \mathrm{~V}_{\mathrm{LV}}=30$ $\mathrm{km} / \mathrm{jam}$, nilai $\mathrm{TT}=24,00$ detik dan nilai tingkat pelayanan jalan $\mathrm{C}$ dari pembahasan diatas dapat ditarik kesimpulan dapat dilihat penurunan jumlah bobot hambatan samping sebesar 29\% menggunakan skenario 3 yang awal nyaa kelas hambatan samping tinggi menjadi rendah, kemudian peningkatan kapasitas sebesar $1,14 \%$ yang sebelumnya 1654 meningkat menjadi 1724, kemudian penurunan nilai derajat kejenuhan sebesar $0,93 \%$ yang sebelumnya 0,46 kemudian menurun menjadi 0,43 .

c. Didapat jumlah bobot hambatan samping tertinggi pada hari rabu pukul 09:30 10:30 sebesar 333, kemudian didapat kapasitas ruas jalan total sebesar 1654 smp/jam, dan nilai derajat kejenuhannya sebesar 0,46 berdasarkan nilai derjat kejenuhan diatas didapat tingkat pelayanan jalan $\mathrm{C}$ yaitu kecepatan arus masih stabil, kecepatan dan pergerakan lebih ditentukan oleh volume tinggi

4. Menurut Mardona, M. (2017). Yang meneliti tentang Analisa Tingkat Pelayanan Jalan Akibat Volume Kendaraan. (Simpang Tiga Bersinyal Jalan Ahmad Yani Depan Polres Sorong Kota Sampai Simpang Tiga Bersinyal Jalan Basuki Rahmat Km.8) didapat kesimpulan antara lain :

a. Tingkat kebisingan dalam Leq hitung paling tinggi yang terjadi di ruas Jalan Ahmad Yani sebesar 68,12 dBA yang terjadi pada Lokasi 2 (dua) pada hari Sabtu 16 Januari 2016 pukul 17.00-17.10. Tingkat kebisingan dalam perhitunngan dengan pendekatan rumus BNL yang paling tinggi terjadi di ruas Jalan Ahmad Yani sebesar 69,36 dBA yang terjadi pada Lokasi 1 (satu) pada hari Jumat 15 Januari 2016 pukul 12.00-12.10. Dengan nilai kebisingan yang demikian maka ruas Jalan Ahmad Yani termasuk dalam Zona D yaitu zona untuk lingkungan industri, pabrik, stasiun kereta api dan terminal bus yang tingkat kebisingannya berkisar 60-70 dB.

b. Berdasarkan nilai kebisingan yang diperoleh ,maka tingkat kebisingan lalu lintas kendaaraan pada Jalan Ahmad Yani dengan 2 (dua) titik lokasi berbeda telah melampaui standar baku mutu yang di tetapkan. Menurut Keputusan Menteri Negara Lingkungan Hidup No. KEP48/MENLH/11/1996 untuk kawasan perumahan, rumah sakit, tempat ibadah dan sarana pendidikan.

d. Faktor penyebab kebisingan lalulintas dari Jalan Ahmad Yani bersumber dari kondisi jalan yang terdapat tanjakan, suara klakson angkutan umum, laju kendaraan, serta komposisi kendaraan seperti knalpot racing , pembakaran mesin, pergesekan ban, dan suara rem angin. 


\section{Analisa}

Karakteristik sistem transportasi di ruas jalan utama Kota Sorong adalah :

1. Di ruas jalan utama, terjadi permasalahan kebisingan telah melebihi standar yang berlaku yaitu Keputusan Menteri Negara Lingkungan Hidup No. KEP48/MENLH/11/1996.

2. Kinerja ruas jalan utama Kota Sorong adalah kecepatan arus masih stabil, kecepatan dan pergerakan lebih ditentukan oleh volume tinggi.

3. Ada permasalah on street parking yang menyebabkan macet di beberapa titik di ruas jalan utama Kota Sorong, hal ini disebabkan juga karena beberapa sarana umum tidak mempunyai lahan parkir yang layak sehingga mereka parkir di bahu jalan.

\section{KESIMPULAN}

Karakteristik sistem transportasi di ruas jalan utama Kota Sorong adalah ruas jalan utama mempunyai kinerja yaitu kecepatan arus masih stabil, kecepatan dan pergerakan lebih ditentukan oleh volume tinggi kapasitas lahan parkir di sarana umum belum optimal, nilai kebisingan di ruas jalan utama melebihi standar yang berlaku, dan keberadaan on street parking akibat parkir liar pada ruas jalan utama.

\section{REFERENSI}

1. Pristianto, H. (2016, March 15). Analisa Kebisingan Akibat Aktivitas Transportasi Di Jalan Ahmad Yani Kota Sorong. http://doi.org/10.17605/OSF.IO/Z8B4C

2. Desembardi, F., Sukrisman, A., Pristianto, H., \& Ulayanto, H. (2018, May 10). Analisis Kinerja Ruas Jalan Terhadap Pengaruh Hambatan Samping Pada Jalan A.M. Sangaji Gonof Km.12 Kota Sorong. http://doi.org/10.17605/OSF.IO/XPRTZ

3. Pristianto, H., \& Hidayati, S. N. (2017). Analisa Tingkat Kebisingan Lalu Lintas Di Jalan Basuki Rahmat Kota Sorong. Rancang Bangun, 3(1).

4. Mardona, M. (2017). Analisa Tingkat Pelayanan Jalan Akibat Volume Kendaraan. (Simpang Tiga Bersinyal Jalan Ahmad Yani Depan Polres Sorong Kota Sampai Simpang Tiga Bersinyal Jalan Basuki Rahmat Km.8)

5. Pristianto, H., Amri, I., \& Rusdi, A. (2014, May 9). Pedoman Penulisan Tugas Akhir Fakultas Teknik Universitas Muhammadiyah Sorong 2014. http://doi.org/10.17605/OSF.IO/4VTJM. 